\title{
Hypertension and arterial disease
}

\author{
J. R. A. Mitchell \\ From the Faculty of Medicine, University of Nottingham
}

There is abundant evidence that the height of an individual's systemic arterial pressure is related, in a graded way, to his chances of developing ischaemic heart disease or cerebrovascular disease. The way in which the link operates in respect of coronary disease is not yet known, and further evidence is required before we can accept that the hypertension is necessarily a direct causal factor rather than a marker of some feature in the individual's make-up which is itself linked to the onset of arterial thrombosis (the 'series' or 'parallel' wiring dilemma). In respect of haemorrhagic stroke not only have we a link but we also have a mechanism of action plus evidence that pressure reduction can modify the risk. We have a 'series' wired circuit, and the problem now facing us is to acquire the wisdom which will allow us to decide when to seek out hypertension and what we should do when we find it.

The measurement of systemic arterial pressure is one of the few simple yet quantitative assessments of the cardiovascular system which can be made in our day-to-day clinical practice. The adverse effects of significantly raised pressure levels were recognized within a few decades of the development of reliable methods for measuring arterial pressure, and by 1913 Janeway was already pointing out that high arterial pressure can kill or disable because of its effects on the heart and arteries. In view of the major contribution made by vascular disease to the death rate in countries such as our own (Table I) we need to understand the role of hypertension in this mortality experience. If it plays a major part, then as blood pressure can be readily measured, and as it can then be satisfactorily controlled by hypotensive agents, ought we to be able to alter the pattern of vascular disease in a total community? To explore the background to this far-reaching concept, I propose to consider how raised arterial pressure is related to clinically manifest coronary arterial disease, to actual disease of the artery walls, and to cerebral haemorrhage.

\section{Hypertension and coronary disease}

The true relation between hypertension and the onset of ischaemic heart disease could not be determined by the most obvious and readily available method - namely, the measurement of the blood pressure levels of patients with cardiac infarction and comparison with an age-matched group of individuals who had not sustained cardiac infarcts. The two reasons for this are self-evident but bear restating. First, 5o per cent of the deaths in this condition occur within the initial 2 hours of the episode (Fulton, Julian, and Oliver, 1969), so no pressure recordings may be made before death. The blood pressure levels of the available survivors must therefore be used for analysis, and these may be quite unrepresentative. Second, the infarction itself may modify the subsequent blood pressure pattern, and levels which bear no relation to those which antedated the episode may therefore be used for analysis. These problems are inherent in any retrospective study where one waits for infarction to occur and only then measures blood pressure. The alternative method is to assess the level of blood pressure in a large population sample and then sit back and wait until some of the group develop manifestations of coronary disease. This prospective approach was used in the Framingham survey, and we are perpetually indebted to the pioneer workers who organized this study, for their results provided areas of solid fact where hitherto we had been floundering in a swamp of speculation. The Framingham group (Kagan et al., 1962) showed that the risk of developing coronary heart disease in an eight-year survey period was directly correlated with the systolic and diastolic pressure levels on initial entry to the study (Table 2). The figures show that a man is six times more likely to develop coronary disease if his systolic pressure is over 180 than if it is under 120 , while for women the multiplying factor is a ninefold increase between the highest and lowest pressures. 
TABLE I Death rate per million living from malignant disease and vascular disease, U.K. 1967

\begin{tabular}{lll}
\hline Age group & All neoplasms & All vascular disease \\
\hline $65-74$ & 19,235 & 36,617 \\
$75-84$ & 29,248 & 98,272 \\
\hline
\end{tabular}

(Registrar General, 1968.)

TABLE 2 Risk of developing coronary heart disease in 8-year survey period, according to initial systolic blood pressure level. Morbidity ratio $=$ observed cases/expected cases $\times 100$

\begin{tabular}{|c|c|c|}
\hline \multirow{2}{*}{$\begin{array}{l}\text { Initial systolic } \\
\text { blood pressure } \\
\text { (mm. } \mathrm{Hg})\end{array}$} & \multicolumn{2}{|l|}{ Morbidity ratio } \\
\hline & Men aged $30-59$ & Women aged 40-59 \\
\hline Under 120 & 36 & 24 \\
\hline $120-139$ & 92 & 52 \\
\hline $140-159$ & 98 & 87 \\
\hline $160-179$ & 160 & I77 \\
\hline $180+$ & 227 & 219 \\
\hline
\end{tabular}

(Kagan et al., 1962.)

Two crucial points emerge from these results: firstly, that these pressures were recorded in a routine or 'casual' way and it is pointless therefore to plead that a patient with elevated pressure levels can be ignored because the readings were made under the stress of a clinic visit. Casual pressure levels clearly are of significance, and it is quite foolish to place a patient in bed for several days, often under sedation, in order to demonstrate that his pressure can fall to levels which are more acceptable to the physician. Such pressure reductions can occur during sleep in subjects with extremely high casual pressures (Richardson et al., 1964), and should not lull the observer into a false sense of security, for it is the casual pressure which is so clearly linked to mortality experience. The second point to emerge from the Framingham data is the smooth gradation of risk as pressure increases; this reinforces the point made so cogently by Pickering in his many contributions to this field (Pickering, I96I) that blood pressure is a quantity: the more of it you have, the more you are at risk. There is clearly no magic dividing line between normotension and hypertension, and this accords with the vast experience accumulated by the life insurance companies (Table 3 ). The figures show that even at these modest levels of pressure, risk is proportional to the height of pressure.

We must constantly bear in mind that correlation does not imply causation; there are two wiring diagrams for our proposed circuit (Table 4). If hypertension is in series with coronary disease, then modifying the pressure level will modify an individual's infarctionproneness; if, however, hypertension is a reflection of the possession of some other factor which itself produces infarction, so that the wiring diagram is in parallel, then pressurereduction cannot alter the infarction pattern. This is amenable to testing, and though the long-term studies carried out under the auspices of the Veterans Administration (Freis, I967) suggest that hypotensive agents can reduce the death rate from cardiac infarction this has not been the experience of other workers (Breckenridge, Dollery, and Parry, 1970). The patients entering such trials are already highly selected, and we should not use these results as definitive evidence for or against the 'series-wiring' concept. The 'parallel-wiring' concept is given an interesting fillip by the studies of Hinkle et al. (1966) who carried out a prospective, Framinghamtype survey in the Bell Telephone System. As in Framingham, significant correlations between episodes of coronary disease and an individual's smoking habit, serum lipids, and blood pressure level were observed, but Hinkle and his colleagues also found that an equally valid discriminant was the level of educational attainment of the participants, 'no-college' men faring significantly worse than 'college' men.

Of interest to us in our present task is that raised arterial pressure, and left ventricular enlargement on radiography were more common in young 'no-college' men than in 'college' men. Further probing revealed just how multifactorial is the background to the whole situation. Thus 'no-college' men are clearly different from 'college' men in many ways over and above their arterial pressure levels (they smoke more, they are more often obese, and they are less physically active). Not only are they different, but their relatives are also

TABLE 3 Deaths from heart and circulatory diseases in men according to initial blood presure level, expressed as a ratio of the standard risk

\begin{tabular}{ll}
\hline Pressure $(\mathrm{mm} . \mathrm{Hg})$ & Ratio of standard risk \\
\hline $\begin{array}{c}\text { Systolic } 138-147 \\
\text { or diastolic } 83-92\end{array}$ & $\mathrm{1} \cdot 4$ \\
$\begin{array}{c}\text { Systolic } 138-147 \\
\text { and diastolic 83-92 }\end{array}$ & $\mathrm{1} \cdot 8$ \\
$\begin{array}{c}\text { Systolic } 148-177 \\
\text { or diastolic 93-102 }\end{array}$ & $\mathbf{2} \cdot \mathrm{I}$ \\
$\begin{array}{c}\text { Systolic } 148-177 \\
\text { and diastolic 93-102 }\end{array}$ & $2 \cdot 8$ \\
\hline
\end{tabular}

(Metropolitan Life Insurance Company, 196r.) 
TABLE 4 Alternative wiring diagrams for mode of action of risk factors

\begin{tabular}{cc}
\hline Series circuit & Parallel circuit \\
\hline Factor X & Factor X \\
$\downarrow$ & $\frac{1}{\downarrow}$ \\
Identifiable & $\downarrow$ \\
'risk' factor & Event Identifiable \\
$\downarrow$ & 'risk' factor \\
Event & \\
\hline
\end{tabular}

different ('no-college' men had parents who died earlier and whose deaths were more often attributed to circulatory disease and to high blood pressure). This fascinating study shows that we must keep the possibility of the 'parallel-wiring' diagram in our mind, for these Bell Telephone men contained many factors which determined what they were and what they did, one expression of the differences between the various groups being the height of the arterial pressure. This may, however, be serving merely as a marker of the underlying differences between individuals rather than being a causal mediator in a chain of pathogenetic mechanisms.

\section{Hypertension and arterial disease}

Having established that the height of an individual's arterial pressure is correlated with his chance of developing clinically detectable coronary disease, we need to seek a mechanism by which this link can operate. As cardiac infarction is a manifestation of coronary arterial thrombosis (Mitchell and Schwartz, 1965), is thrombotic occlusion more common with increasing pressure levels? Unfortunately, no valid evidence is available on this point because of the paucity or lack of validity of the blood pressure levels in cases which become available for study at necropsy. A prospective study of the Framingham type, leading on to a quantitative pathological assessment after death, would be of vital interest, but the difficulties inherent in setting up such a survey should not be underestimated.

If the link between hypertension and thrombosis has received inadequate attention, then the sizeable body of information on the effect of raised pressure on 'atherosclerosis' both in man and in experimental animals ought to redress the balance. Unhappily, the differences between the various types of plaque in man and between spontaneous human disease and animal lesions have often been forgotten. Moreover, the methods for assessing the extent of the disease have usually been subjective, and in the final analysis the difficulty of separately assessing linked vari- ables has been forgotten. Thus if blood pressure increases with age and plaque severity increases with age, then blood pressure is bound to correlate with plaque severity.

In an attempt to overcome some of these problems my colleagues and I (Mitchell, Schwartz, and Zinger, 1964) studied a defined segment of the aorta by a detailed quantitative technique, and measured separately the various types of plaque. We excluded from the analysis patients in whom valid pressure readings were not available and we submitted the data to multiple correlation analysis by computer, so as to assess the effect of each variable independent of the others. We found that the flat 'fatty streaks' did not correlate with any of the factors considered, whereas the various types of raised lesion were related to these factors. We concluded that the reasons for linking the two types of lesion by regarding them as manifestations of a single disease process were tenuous and that further work was required to clarify their relationship. The area affected by raised plaques was correlated with age and with blood pressure level, but the separate effect of pressure was a small one, and our most significant finding was that from 60 to 80 per cent of the variability of these raised lesions was unaccounted for by the factors we were considering. The nature of this residual variation still requires to be sought.

Thus in contrast to small arterioles, where the effects of raised arterial pressure are readily demonstrable, its effect on the amount of disease in large vessels is not very great. The pathological basis for the epidemiological findings in surveys such as the one carried out in Framingham remains uncertain.

\section{Hypertension and cerebral haemorrhage}

As we have seen, there is a close epidemiological and actuarial link between the risk of developing clinically manifest coronary disease and the height of the casual arterial pressure. There is an equally striking link between systemic pressure and the risk of developing a cerebral vascular accident. Such accidents make a highly significant contribution to middle-aged mortality (death rate per million aged $65-74$ in the United Kingdom: neoplasms 19,235, vascular lesions of the nervous system 10,623 ; at age $75-84$ the rates are 29,248 and 33,487 , respectively).

One must accept that the figures for total vascular lesions of the nervous system will obscure the relative contributions of haemorrhage and infarction because of the virtual impossibility of accurate differentiation between these conditions, save by necropsy 
examination (Mitchell, 1968). There is thus no definitive survey, of Framingham type, to which one can turn for clarification of the relation between stroke and hypertension. However, even within the narrow range of pressures accepted by life insurance offices for the granting of policies, an even more striking link than was shown in Table 3 can be demonstrated (Table 5). Once again we see the steady gradation of risk with rising pressure levels and the substantial contribu-

TABLE 5 Deaths from vascular lesions of the central nervous system according to initial blood pressure level, expressed as a ratio of the standard risk

\begin{tabular}{ll}
\hline Pressure $(\mathrm{mm} . \mathrm{Hg})$ & Ratio of standard risk \\
\hline $\begin{array}{c}\text { Systolic } 138-147 \\
\text { or diastolic } 83-92\end{array}$ & $\mathrm{I} \cdot 6$ \\
$\begin{array}{c}\text { Systolic } 138-147 \\
\text { and diastolic 83-92 }\end{array}$ & $2 \cdot 4$ \\
$\begin{array}{c}\text { Systolic } 148-177 \\
\text { or diastolic 93-102 }\end{array}$ & $3 \cdot 0$ \\
$\begin{array}{c}\text { Systolic 148-177 } \\
\text { and diastolic 93-102 }\end{array}$ & $6 \cdot 2$ \\
\hline
\end{tabular}

(Metropolitan Life Insurance Company, 196r.)

tion of even quite modest elevations of pressure.

There is abundant evidence that hypertension is more closely correlated with cerebral haemorrhage than with cerebral infarction (ranging from the 'hardness' of the pulse in apoplexy noted by Wepfer in 1724 to the classic studies of Aring and Merritt in 1935). What has been debated over the years is the way in which this relation arises and the nature of the process by which primary intracerebral haemorrhage arises. In 1868 Charcot and Bouchard showed that the small intracerebral arteries in patients with cerebral haemorrhage bore saccular aneurysms of 250-400 microns diameter. Subsequent workers claimed that these were artefacts or that they were the consequence of the haemorrhage rather than its cause. Two recent studies have served to support Charcot and Bouchard's original view. Russell (1963) adapted to the cerebral circulation the technique which Schwartz and I had used for the coronary tree and in 54 brains was able to show considerable numbers of microaneurysms particularly in the basal ganglia, where, of course, primary cerebral bleeding so commonly occurs. He found a close relation between aneurysm-prevalence and blood pressure level (Table 6). Cole and Yates (1967) made a more detailed study of these microaneurysms and showed that their distribution closely paralleled the sites of election of primary intracerebral bleeding (of
200 brains examined 53 had hemisphere lesions, 15 had brain stem lesions, and 4 had cerebellar lesions). They also found a close relationship between aneurysm prevalence and blood pressure level (Table 7).

As with coronary disease, there is an epidemiological link between an event (in this case intracerebral haemorrhage) and blood pressure level. Unlike the blood pressure/ coronary disease correlation, which remains unexplained, there is a pathological mechanism by which this link might arise - namely, that raised arterial pressure produces microaneurysms in certain parts of the brain and that these lesions subsequently rupture, allowing blood to plough up the brain. Cole and Yates (1967) sum up the present situation very succinctly in the discussion of their results:

'It is felt that hypertension plays a dominant role in the cause of classical cerebral haemorrhage, and as hypertension can be adequately controlled in many cases such haemorrhage is, to a large extent, a preventable disease. These facts are already well appreciated, but by throwing some light on the lesion that can link hypertension and haemorrhage we wish to re-emphasize this fundamental connexion.

'We have no evidence as to how long hypertension must be present before aneurysms appear, or of the fate of the lesions if the blood pressure is reduced to normal levels. It seems unjustifiable to regard even symptomless hypertension as anything but potentially harmful. Though the high blood pressure itself may not be producing symptoms it is in many cases inducing aneurysms, which can eventually rupture to cause haemorrhage.'

This, then, is the therapeutic and preventive challenge. There is considerable evidence from studies such as those of Leishman (1959), Hamilton, Thompson, and Wisniewski (1964), Smirk (1966), and Freis (1967) that a significant reduction in the death rate from cerebrovascular accidents can be produced by regimens which are reasonably acceptable to

TABLE 6 Prevalence of intracerebral microaneurysms in relation to blood pressure level, expressed as the number of brains showing the stated number of aneurysms

\begin{tabular}{|c|c|c|c|c|c|}
\hline \multirow{2}{*}{$\begin{array}{l}\text { Pressure group } \\
(\mathrm{mm} . \mathrm{Hg})\end{array}$} & \multicolumn{5}{|c|}{ Prevalence of aneurysms } \\
\hline & 0 & $I-5$ & $6-10$ & $>I O$ & $\begin{array}{l}\text { Poor } \\
\text { injection }\end{array}$ \\
\hline $\begin{array}{l}\text { Diastolic under I ro } \\
\quad n=38 \\
\text { Diastolic over I Io }\end{array}$ & 25 & 7 & 2 & I & 3 \\
\hline $\mathrm{n}=\mathrm{I} 6$ & $\mathbf{I}$ & 5 & 5 & 4 & $\mathbf{I}$ \\
\hline
\end{tabular}

(Russell, 1963.) 
TABLE 7 Prevalence of intracerebral microaneurysms in relation to blood pressure level, expressed as the percentage of brains examined in which aneurysms were found

\begin{tabular}{ll}
\hline Group & $\begin{array}{l}\text { Prevalence of } \\
\text { aneurysms per cent }\end{array}$ \\
\hline Diastolic under I IO mm.Hg & 7 \\
Diastolic over I IO mm.Hg & 35 \\
Massive cerebral haemorrhage & 86 \\
\hline
\end{tabular}

(Cole and Yates, 1967.)

patients. What we do about these results constitutes a sociological problem (to what extent will symptomless subjects who have been found to be hypertensive at some chance examination be prepared to take tablets, which may make them feel unwell, in order to prevent a process which they may not readily comprehend and which may never happen to them as individuals, whether treated or untreated ?) There is already substantial evidence that members of the community view such matters in a different light from their medical advisers, for if individuals were actively concerned with the preservation of their health from known and very obvious hazards all our patients would be non-smokers and all of them would wear seat-belts every time they ride in a car. As they do not adopt these simple lifepreserving measures we should reflect before we embark on massive screening programmes and on wholesale prophylactic hypotensive therapy.

\section{References}

Aring, C. D., and Merritt, H. H. (1935). Differential diagnosis between cerebral hemorrhage and cerebral thrombosis. Archives of Internal Medicine, 56, 435.

Breckenridge, A., Dollery, C. T., and Parry, E. H. O. (1970). Prognosis of treated hypertension: changes in life expectancy and causes of death between 1952 and 1967. Quarterly Fournal of Medicine, 39, 4I I.

Charcot, J. M., and Bouchard, C. (1868). Nouvelles recherches sur la pathogénie de l'haemorrhagie cérébrale. Archives de Physiologie, Normale et Pathologique, I, I 10, 643, 725.
Cole, F. M., and Yates, P. O. (1967). The occurrence and significance of intracerebral micro-aneurysms. Fournal of Pathology and Bacteriology, 93, 393.

Freis, E. D. (1967). Effects of treatment on morbidity in hypertension. Fournal of the American Medical Association, 202, 1028.

Fulton, M., Julian, D. G., and Oliver, M. F. (1969). Sudden death and myocardial infarction. Circulation, 39-40, Suppl. 4, 182.

Hamilton, M., Thompson, E. N., and Wisniewski, T. K. M. (1964). The role of blood-pressure control in preventing complications of hypertension. Lancet, $1,235$.

Hinkle, L. E., Jr., Benjamin, B., Christenson, W. N., and Ullmann, D. S. (1966). Coronary heart disease: 30-year experience of 1,160 men. Archives of Environmental Health, 13, 312.

Janeway, T. C. (1913). A clinical study of hypertensive cardiovascular disease. Archives of Internal Medicine, 12, 755.

Kagan, A., Dawber, T. R., Kannel, W. B., and Revotskie, N. (1962). The Framingham study: a prospective study of coronary heart disease. Federation Proceedings, 21, Suppl. 2, 52.

Leishman, A. W. D. (1959). Hypertension - treated and untreated: a study of 400 cases. British Medical Fournal, 1, 136r.

Metropolitan Life Insurance Company (196I). Blood Pressure: Insurance Experience and Its Implications. New York.

Mitchell, J. R. A. (1968). The pathogenesis of cerebral haemorrhage and cerebral infarction. In Biochemical Aspects of Neurological Disorders, 3rd series, p. 142. Ed. by J. N. Cumings and M. Kremer. Blackwell, Oxford.

-, and Schwartz, C. J. (1965). Arterial Disease. Blackwell, Oxford.

,-- , and Zinger, A. (1964). Relationship between aortic plaques and age, sex and blood pressure. British Medical fournal, 1, 205.

Pickering, G. W. (1961). The Nature of Essential Hypertension. Churchill, London.

Registrar General (1968). Statistical Review of England and Wales for 1967, Part I, Medical Tables. H.M.S.O., London.

Richardson, D. W., Honour, A. J., Fenton, G. W., Stott, F. H., and Pickering, G. W. (I964). Variation in arterial pressure throughout the day and night. Clinical Science, 26, 445.

Russell, R. W. R. (1963). Observations on intracerebral aneurysms. Brain, 86, 425.

Smirk, F. H. (1966). Prognosis in retinal Grade I and II patients. In Antihypertensive Therapy, p. 355. Ed. by F. Gross. Springer, Berlin.

Wepfer, J. J. (1 724). Historiae Apoplecticorum. JassonioWaesbergios, Amsterdam. 